\title{
Tree nut, peanut, and peanut butter intake and risk of postmenopausal breast cancer: The Netherlands Cohort Study
}

\author{
Piet A. van den Brandt ${ }^{1,2}$ D Lisette Nieuwenhuis $^{1}$
}

Received: 19 July 2017 / Accepted: 30 October 2017 / Published online: 22 November 2017

(C) The Author(s) 2017. This article is an open access publication

\begin{abstract}
Purpose Nut intake has been associated with reduced mortality and risk of cardiovascular diseases, but there is only limited evidence on cancer. We investigated the relationship between nut intake and risk of postmenopausal breast cancer, and estrogen/progesterone receptor (ER/PR) subtypes.

Methods In The Netherlands Cohort Study, 62,573 women aged 55-69 years provided information on dietary and lifestyle habits in 1986. After 20.3 years of follow-up, 2,321 incident breast cancer cases and 1,665 subcohort members were eligible for multivariate case-cohort analyses.

Results Total nut intake was significantly inversely related to ER negative (ER -) breast cancer risk, with HR 0.55 (95\% CI $0.33-0.93$ ) for those consuming at least $10 \mathrm{~g}$ nuts/day versus non-consumers ( $p$ trend $=0.025$ ). There were no significant inverse associations with ER + or total breast cancer. While there was no variation between PR subtypes, the ER-PR- subtype was also significantly inversely associated with nut intake, with HR 0.53 (95\% CI 0.29-0.99), $p$ trend $=0.037$. Intake of peanuts and tree nuts separately was also inversely related to ER - breast cancer subtypes, while no associations were found with peanut butter intake.

Conclusions Our findings suggest an inverse association between nut intake and ER - breast cancer, and no association with total or hormone receptor-positive subtypes.
\end{abstract}

Keywords Breast cancer $\cdot$ Nuts $\cdot$ Peanuts $\cdot$ Peanut butter $\cdot$ Cohort study

\section{Introduction}

Nut intake has been associated with reduced risk of noncommunicable diseases such as cardiovascular diseases (CVD) and diabetes [1]. Apart from CVD, interest is growing in mortality and other health effects as well, stimulated by the PREDIMED trial showing effects of Mediterranean diet supplemented with mixed nuts or olive oil on CVD

Electronic supplementary material The online version of this article (https://doi.org/10.1007/s10552-017-0979-7) contains supplementary material, which is available to authorized users.

Piet A. van den Brandt

PA.vandenBrandt@maastrichtuniversity.nl

1 Department of Epidemiology, Maastricht University Medical Centre, Care and Public Health Research Institute (CAPHRI), Maastricht, The Netherlands

2 Department of Epidemiology, GROW- School for Oncology and Developmental Biology, Maastricht University Medical Centre, PO Box 616, 6200 MD Maastricht, The Netherlands and depression [2]. In several cohort studies, nut intake has been associated with lower total mortality and cancer mortality, e.g., [3-5], but few studies have been done on nut intake and risk of cancer. Also, little is known on differences between tree nuts and peanuts, and whether peanut butter shows similar associations with risk as peanuts. In addition, dose-response relationships remain unclear.

For breast cancer, two cohort studies have investigated the association between nut intake and breast cancer risk $[6,7]$; both found no association with overall breast cancer risk. However, no distinction was made between tree nuts, peanuts, and peanut butter (these were grouped). One recent large population-based case-control study showed a significant inverse association between total nut intake in adolescent years and breast cancer (OR 0.76), with a stronger association for postmenopausal than premenopausal breast cancer [8]. Recent evidence from a randomized controlled trial on primary prevention of cardiovascular diseases indicated a potentially strong protective effect of Mediterranean diet supplemented with nuts on the risk of postmenopausal 
breast cancer in Spain; however, this was not significant, probably due to small number of cases during short followup [9]. For proliferative benign breast disease, a cohort study showed that two or more servings of nuts per week during adolescence were inversely associated with $36 \%$ lower risk of benign breast disease, compared with an intake of less than one serving per month. Statistically significant inverse associations were also observed for peanut intake alone [10].

It is important to distinguish between pre- and postmenopausal breast cancer, as well as estrogen/progesterone receptor (ER/PR) subtypes, because of differences in etiology.

We investigated the association between intakes of total nuts, tree nuts, peanuts, and peanut butter, and postmenopausal breast cancer risk, overall and stratified by hormone receptor status, in The Netherlands Cohort Study (NLCS). We recently found an inverse association between Mediterranean Diet (MD)-adherence and ER - breast cancer in the NLCS [11], in which nuts seemed to play a dominant role. Here, we further investigated this and evaluated tree nuts, peanuts, and peanut butter separately, while controlling for MD adherence.

\section{Materials and methods}

\section{Study design and cancer follow-up}

The NLCS started in September 1986 and the female part included 62,573 women aged 55-69 years [12]. At baseline, participants completed a mailed, self-administered questionnaire on cancer risk factors. The NLCS study was approved by institutional review boards from Maastricht University and The Netherlands Organization for Applied Scientific Research. All cohort members consented to participation by completing the questionnaire. For data processing and analysis, the case-cohort method was used [13]. Accumulated person-years in the cohort were estimated from a subcohort ( $n=2589$ women), randomly sampled from the cohort immediately after baseline. These subcohort members were actively followed up biennially for vital status information. The follow-up of the subcohort was $100 \%$ complete at 20.3 years of follow-up.

Follow-up for cancer incidence in the entire cohort was established by annual record linkage with The Netherlands Cancer Registry and PALGA, the nationwide Dutch Pathology Registry [14]. Completeness of follow-up through record linkage with cancer registries and PALGA was estimated to be greater than $95 \%$ [15]. After 20.3 years of follow-up (17 September 1986, until 1 January 2007), a total of 3,354 incident breast cancer cases (of whom 144 were also subcohort member) were detected among women. Cases and subcohort members were excluded if they reported a history of cancer (except skin cancer) at baseline and if their dietary data were incomplete or inconsistent [16]. Figure S1 (Supplementary data) shows the selection and exclusion steps that resulted in the number of cases and female subcohort members that were included in the analysis. There were 1665 subcohort members and 2,321 breast cancer cases available for analysis. As with the nested case-control study, the case-cohort study is also nested within a cohort with comparable efficiency gain. An additional advantage of the case-cohort design over the nested case-control design is that the selected subcohort can be used to study a range of disease endpoints [17].

\section{Exposure assessment}

The 11-page baseline questionnaire measured dietary intake, detailed smoking habits, anthropometry, physical activity, and other risk factors related to cancer [12]. Habitual consumption of food and beverages during the year preceding baseline was assessed using a 150-item semi-quantitative food-frequency questionnaire, which was validated against a 9-day diet record [16]. Nut and peanut butter consumption was assessed by asking frequency and portion size of intake of 'peanuts,' 'other nuts, mixed nuts,' and 'peanut butter.' Frequency of consumption could range from 'never or less than $1 \mathrm{x} /$ month' to ' $6-7 \mathrm{x} /$ week.' In addition, participants could fill in the number of standard portion sizes they consumed per intake. For tree nuts and peanuts, a standard portion size was $28 \mathrm{~g}$. A standard portion size of peanut butter, a particularly popular spread in The Netherlands, was $15 \mathrm{~g}$ per slice of bread. Consumption frequencies and portion sizes were multiplied to calculate mean daily intakes in grams. Total nut intake was calculated as the sum of peanuts and other nuts. Nutrient intakes were calculated using the computerized Dutch food composition table [18].

\section{Statistical analysis}

For the intakes of nuts and peanut butter, the mean (SD) values were calculated in the subcohort. The distribution of the subcohort members by nut intake level and various characteristics was examined by cross-tabulations and summary statistics.

The relationship between intake of nuts and breast cancer risk was evaluated using Cox proportional hazards models. It was verified that the proportional hazards assumption was not violated using Schoenfeld residuals [19] and $-\ln (-\ln )$ survival plots. Standard errors were estimated using the robust Hubert-White sandwich estimator to account for additional variance introduced by the subcohort sampling [20].

In age- and multivariable-adjusted survival analyses, total nut intake was evaluated and tested on categorical $(0,0.1-<5,5-<10,10+$ g/day $)$ and continuous scales. In 
multivariable analyses, hazard ratios (HRs) were corrected for potential confounders: age at baseline (55-59, 60-64, 65-69 years), cigarette smoking status (never, former, current), frequency (number of cigarettes per day; continuous, centered), duration (number of years; continuous, centered), body height (continuous, $\mathrm{cm})$, BMI $(<18.5,18.5-<25$, $\left.25-<30, \geq 30 \mathrm{~kg} / \mathrm{m}^{2}\right)$, non-occupational physical activity ( $\leq 30,>30-60,>60-90,>90 \mathrm{~min} /$ day), highest level of education (primary school or lower vocational, secondary or medium vocational, and higher vocational or university), family history of breast cancer in mother or sisters (no, yes), history of benign breast disease (no, yes), age at menarche $(\leq 12,13-14,15-16, \geq 17$ years), parity (nulliparous, $1-2$, $\geq 3$ children), age at first birth $(<25, \geq 25$ years $)$, age at menopause $(<45,45-49,50-54, \geq 55$ years), oral contraceptive use (never, ever), postmenopausal hormone replacement therapy (never, ever), energy intake (continuous, kcal/day), alcohol intake $(0,0.1-<5,5-<15,15-<30, \geq 30 \mathrm{~g} /$ day $)$. Because we recently found an association between Mediterranean diet adherence and breast cancer risk [11], we additionally adjusted for adherence to the Mediterranean diet as measured with the alternate Mediterranean diet (aMED) score [21]. Since nuts comprise one of the components of the aMED-score and because alcohol consumption is positively associated with breast cancer risk, an adapted version (excluding nuts and alcohol) was used here, which ranged from 0 (no adherence) to 7 (maximal adherence).

Linear trends between nut intake categories and breast cancer were evaluated with Wald tests, after fitting median values of nut consumption per intake category as continuous terms in the regression model. Median values were based on the distribution of the variables in the subcohort. Analyses were also done for peanuts and tree nuts separately, and peanut butter; because of lower numbers in the high intake categories, we used categories $0,0.1-<5,5+\mathrm{g} /$ day.

Besides overall postmenopausal breast cancer, we conducted these analyses for subtypes defined by hormone receptor status: $\mathrm{ER}+, \mathrm{ER}-, \mathrm{PR}+, \mathrm{PR}-, \mathrm{ER}+\mathrm{PR}+$, and ER-PR. Differences in associations with nut intake between breast cancer subtypes were tested using a heterogeneity test [22], in which the standard error for the observed difference in rate ratios was estimated using a bootstrapping method developed for the case-cohort design [23].

To further investigate the dose-response relations between nut consumption and breast cancer risk, restricted cubic splines with three fixed knots $(0,5$, and $10 \mathrm{~g} /$ day $)$ were used to graphically present the dose-response curves without making a priori assumptions about their shapes. Wald tests were performed to evaluate the linearity of these relationships.

To evaluate potential residual confounding by breast cancer risk factors, and effect modification, analyses of MDscores and breast cancer were also conducted within strata of alcohol intake, BMI, physical activity, and adapted aMEDscore. Interactions with these factors were tested using Wald tests and cross-product terms. In sensitivity analyses, we repeated analyses after excluding cancers (and person-years) occurring in the first 2 years of follow-up. Moreover, analyses of peanut butter consumption were repeated, restricted to respondents who had stated having had the same peanut butter intake during the 5 years before baseline. Unfortunately, these data were unavailable for total nut, tree nut, and peanut consumption.

Analyses were performed using Stata version 12; presented $p$ values are two-sided, with $p<0.05$ considered as statistically significant.

\section{Results}

Mean total nut consumption (SD) in subcohort women was $4.3(8.4) \mathrm{g} /$ day; for tree nut, peanut, and peanut butter, these values were 1.0 (3.9), 3.3 (6.9), and 1.2 (3.6), respectively. Nut consumers were on average somewhat younger (Table 1), leaner, drank more alcohol, less often reported a positive family history of breast cancer, and were less often never smokers. They were higher educated, more often had a late age at birth of their first child, scored higher on the adapted aMED-score, and more often used oral contraceptives and postmenopausal HRT. Peanut butter intake was weakly positively associated with nut intake.

Peanut butter consumers were on average somewhat younger (Table 1), leaner, drank less alcohol, less often reported a history of benign breast disease or family history of breast cancer, and were more often never smokers, but were higher educated, more often had a late age at birth of first child, scored higher on the adapted aMED-score, and more often used oral contraceptives and less often postmenopausal HRT.

Table 2 shows results of age-adjusted and multivariableadjusted analyses of the associations of total nut intake with total breast cancer risk, and risk of estrogen and progesterone receptor subtypes. Total nut intake was not associated with total breast cancer risk in categorical or continuous analyses. Compared to non-consumers of nuts, the HR (95\% $\mathrm{CI})$ of breast cancer for those consuming at least $10 \mathrm{~g}$ nuts/ day was $0.91(0.72-1.14)$ ( $p$ trend $=0.625)$ in multivariable analyses. Additional analyses adjusting for peanut butter intake yielded similar results (data not shown). ER + breast cancer also showed no associations, but ER - breast cancer was significantly inversely associated with total nut intake. Compared to non-consumers of nuts, the HRs $(95 \%$ CIs) of ER - breast cancer for those consuming $0.1-<5$, $5-<10$, or at least $10 \mathrm{~g}$ nuts/day, were $0.78(0.56-1.08)$, $0.60(0.34-1.05)$, and $0.55(0.33-0.93)$, respectively ( $p$ trend $=0.025)$. No clear associations were seen for PR 
Table 1 Baseline characteristics [mean (SD), or percentage] according to category of total nut intake in subcohort women with complete dietary data, Netherlands Cohort Study

\begin{tabular}{|c|c|c|c|c|c|c|c|}
\hline \multirow[t]{2}{*}{ Characteristic } & \multicolumn{4}{|c|}{ Total nut intake (g/day) } & \multicolumn{3}{|c|}{ Peanut butter intake (g/day) } \\
\hline & $\begin{array}{l}0 \mathrm{~g} / \text { day } \\
(n=821)\end{array}$ & $\begin{array}{l}0.1-<5 \\
(n=735)\end{array}$ & $\begin{array}{l}5-<10 \\
(n=225)\end{array}$ & $\begin{array}{l}10+\text { g/day } \\
(n=246)\end{array}$ & $\begin{array}{l}0 \mathrm{~g} / \text { day } \\
(n=1493)\end{array}$ & $\begin{array}{l}0.1-<5 \\
(n=351)\end{array}$ & $\begin{array}{l}5+\mathrm{g} / \text { day } \\
(n=183)\end{array}$ \\
\hline Age (years) & $62.2(4.4)$ & $61.1(4.2)$ & $60.1(4.0)$ & $60.6(3.9)$ & $61.6(4.3)$ & $60.9(4.0)$ & $60.7(4.0)$ \\
\hline Height (cm) & $164.9(6.5)$ & $165.5(5.8)$ & $165.6(6.0)$ & $165.8(6.2)$ & $165.4(6.1)$ & $165.1(6.0)$ & $165.2(6.6)$ \\
\hline BMI $\left(\mathrm{kg} / \mathrm{m}^{2}\right)$ & $25.3(3.8)$ & $25.1(3.4)$ & $24.4(3.1)$ & $24.5(3.3)$ & $25.0(3.6)$ & $25.2(3.4)$ & $24.4(3.2)$ \\
\hline Physical activity (min/day) & $62.9(55.2)$ & $65.8(48.1)$ & $71.7(55.1)$ & $60.8(37.4)$ & $62.3(48.4)$ & $72.8(60.0)$ & $68.3(49.2)$ \\
\hline Age at menarche (years) & $13.7(1.8)$ & $13.6(1.7)$ & $13.7(1.8)$ & $13.6(1.7)$ & $13.6(1.7)$ & $13.7(1.9)$ & $13.8(1.9)$ \\
\hline Age at menopause (years) & $48.7(4.4)$ & $48.7(4.6)$ & $49(4.4)$ & $48.9(4.3)$ & $48.7(4.5)$ & $48.6(4.4)$ & $49.6(4.2)$ \\
\hline Alcohol intake (g/day) & $4.9(9.5)$ & $5.8(8.8)$ & $7.2(9.3)$ & $8.6(10.9)$ & $6.1(9.7)$ & $5.5(9.1)$ & $4.9(7.9)$ \\
\hline Peanut butter intake (g/day) & $1.0(3.5)$ & $1.2(3.7)$ & $1.3(3.5)$ & $1.3(3.3)$ & & & \\
\hline Total nut intake (g/day) & & & & & $4.1(8.3)$ & $5.2(8.7)$ & $4.9(8.5)$ \\
\hline Never smoker (\%) & 60.7 & 59.3 & 49.8 & 50.4 & 57.9 & 54.7 & 62.3 \\
\hline University or higher vocational education (\%) & 6.2 & 10.7 & 14.3 & 12.6 & 8.4 & 11.5 & 14.8 \\
\hline Nulliparous (\%) & 17.7 & 20.5 & 16.9 & 17.6 & 18.1 & 19.0 & 22.0 \\
\hline Age at first birth $\geq 30$ years ( $\%$ of parous) & 22.8 & 19.5 & 26.6 & 26.7 & 22.4 & 21.3 & 25.9 \\
\hline Ever used oral contraceptives (\%) & 20.6 & 24.9 & 35.6 & 33.2 & 24.3 & 27.8 & 29.5 \\
\hline Ever used hormone replacement therapy (\%) & 12.2 & 13.8 & 13.3 & 16.4 & 13.8 & 13.5 & 9.7 \\
\hline Family history breast cancer (\%) & 8.4 & 10.2 & 6.7 & 7.7 & 9.1 & 9.1 & 5.5 \\
\hline History benign breast disease (\%) & 6.8 & 9.4 & 8.4 & 6.5 & 8.5 & 6.3 & 6.0 \\
\hline aMEDr ${ }^{\mathrm{a}}$ score (excluding nuts) $5-7$ pts (\%) & 20.5 & 27.3 & 26.7 & 32.1 & 23.4 & 27.9 & 33.3 \\
\hline
\end{tabular}

aMEDr: alternate Mediterranean Diet Score excluding alcohol

subtypes. Risk of ER-PR - breast cancer was significantly inversely related to total nut intake in multivariable-adjusted analyses with a HR for those consuming at least $10 \mathrm{~g}$ nuts/ day versus non-consumers of 0.53 (95\% CI 0.29-0.99) with $p$ trend $=0.037$. The $\mathrm{ER}+\mathrm{PR}+$ subtype showed no significant association with total nut intake (Table 2). Heterogeneity tests across subtypes using bootstrapping were not significant (data not shown). Analyses for the ER+/PR - subtype closely resembled those of ER + subtypes and was therefore not reported; the number of ER -/PR + cases was too small for separate analyses.

Table 3 shows results of multivariable analyses for intake of peanut, tree nuts, and peanut butter separately. For peanuts and tree nuts, the pattern of associations resembled that for total nut intake, i.e., inverse associations were observed for ER - and ER-PR - subtypes, albeit non-significant. For peanuts, the HR (95\% CI) for ER - breast cancer, comparing for $5+$ versus $0 \mathrm{~g} /$ day was $0.63(0.40-1.01)$, with $p$ trend $=0.059$. For tree nuts, this was $0.47(0.21-1.09)$ for the same contrast ( $p$ trend $=0.079$ ). Similarly, for ER-PR - breast cancer the HR $(95 \% \mathrm{CI})$ was 0.46 $(0.17-1.23),(p$ trend $=0.124)$, when comparing for $5+$ versus $0 \mathrm{~g}$ tree nuts/day. Peanut butter intake was not associated with total breast cancer risk or its subtypes (Table 3). Excluding of the first 2 years of follow-up, or limiting the peanut butter analyses to those with stable intake over the past 5 years, did not materially change the results (data not shown).

Restricted cubic spline curves for the HR according to intake of total nuts, peanuts, tree nuts, and peanut butter are shown in separate panels in Fig. 1 for total breast cancer, and in Fig. 2 for ER - breast cancer. None of the tests for non-linearity were statistically significant ( $p$ values are shown in Figure legends). However, for total nuts and $\mathrm{ER}$ - breast cancer, it was borderline significant, and the exposure-response curves for total nuts, peanuts, and tree nuts show a clear leveling off with intake levels above $10 \mathrm{~g} /$ day. Therefore, effect modification and subgroup analyses were conducted using a categorical variable for nut intake: $0,0.1-<5$, and $5+\mathrm{g} /$ day (combined upper category was needed because of sample size).

In Fig. 3, HRs and 95\% CIs for breast cancer and ER subtypes are presented for the two categories of total nut intake $(0.1-<5$ and $5+\mathrm{g} /$ day $)$ versus $0 \mathrm{~g} /$ day, overall, and in subgroups of potential effect modifiers: alcohol intake, BMI, physical activity, and adapted aMED-score (excluding alcohol and nuts). For total breast cancer, no association with nut intake was seen in most subgroups. For total and $\mathrm{ER}+$ breast cancer, there was significant interaction between nut intake and BMI-level, with decreased HRs observed in the subgroup BMI 18.5-<25 [Total breast cancer: HR 0.79 (0.61-1.02); ER+: HR 0.84 (0.61-1.15)], and (significantly) 
Table 2 Hazard Ratio of breast cancer and subtypes, according to total nut intake in multivariable-adjusted analyses, Netherlands Cohort Study

\begin{tabular}{|c|c|c|c|c|c|c|c|}
\hline & \multicolumn{7}{|c|}{ Total nut intake (g/day) (median) } \\
\hline & $\begin{array}{l}0 \mathrm{~g} / \text { day } \\
(0)\end{array}$ & $\begin{array}{l}0.1-<5 \mathrm{~g} / \text { day } \\
(2.1)\end{array}$ & $\begin{array}{l}5-<10 \mathrm{~g} / \text { day } \\
(7.8)\end{array}$ & $\begin{array}{l}10+\mathrm{g} / \text { day } \\
(15.7)\end{array}$ & $p$ trend & $\begin{array}{l}\text { Continuous } \\
\text { per } 10 \mathrm{~g} / \text { day }\end{array}$ & $p$ non-linear \\
\hline \multicolumn{8}{|l|}{ Total breast cancer } \\
\hline No. of cases & 935 & 844 & 251 & 291 & & 2,321 & \\
\hline Person-years in subcohort & 11,322 & 10,646 & 3,067 & 3,897 & & 28,932 & \\
\hline $\begin{array}{l}\text { Age-adjusted HR } \\
(95 \% \mathrm{CI})\end{array}$ & 1 & $\begin{array}{l}0.97 \\
(0.83-1.12)\end{array}$ & $\begin{array}{l}1.02 \\
(0.81-1.27)\end{array}$ & $\begin{array}{l}0.91 \\
(0.74-1.12)\end{array}$ & 0.471 & $\begin{array}{l}1.01 \\
(0.94-1.09)\end{array}$ & \\
\hline $\begin{array}{l}\text { Multivariable-adjusted HR } \\
(95 \% \mathrm{CI})\end{array}$ & 1 & $\begin{array}{l}0.94 \\
(0.80-1.10)\end{array}$ & $\begin{array}{l}1.05 \\
(0.82-1.34)\end{array}$ & $\begin{array}{l}0.91 \\
(0.72-1.14)\end{array}$ & 0.625 & $\begin{array}{l}1.02 \\
(0.94-1.11)\end{array}$ & 0.343 \\
\hline \multicolumn{8}{|l|}{$\mathrm{ER}+$ breast cancer } \\
\hline No. of cases & 436 & 415 & 119 & 151 & & 1121 & \\
\hline $\begin{array}{l}\text { Age-adjusted HR } \\
(95 \% \text { CI })\end{array}$ & 1 & $\begin{array}{l}1.03 \\
(0.86-1.23)\end{array}$ & $\begin{array}{l}1.04 \\
(0.79-1.36)\end{array}$ & $\begin{array}{l}1.01 \\
(0.79-1.29)\end{array}$ & 0.978 & $\begin{array}{l}1.03 \\
(0.95-1.13)\end{array}$ & \\
\hline $\begin{array}{l}\text { Multivariable-adjusted HR } \\
(95 \% \mathrm{CI})\end{array}$ & 1 & $\begin{array}{l}1.02 \\
(0.84-1.24)\end{array}$ & $\begin{array}{l}1.10 \\
(0.82-1.48)\end{array}$ & $\begin{array}{l}1.07 \\
(0.81-1.41)\end{array}$ & 0.589 & $\begin{array}{l}1.06 \\
(0.96-1.17)\end{array}$ & 0.429 \\
\hline \multicolumn{8}{|l|}{ ER - breast cancer } \\
\hline No. of cases & 117 & 87 & 20 & 24 & & 248 & \\
\hline $\begin{array}{l}\text { Age-adjusted HR } \\
(95 \% \mathrm{CI})\end{array}$ & 1 & $\begin{array}{l}0.79 \\
(0.58-1.07)\end{array}$ & $\begin{array}{l}0.64 \\
(0.38-1.07)\end{array}$ & $\begin{array}{l}0.58 \\
(0.36-0.93)\end{array}$ & 0.022 & $\begin{array}{l}0.84 \\
(0.66-1.06)\end{array}$ & \\
\hline $\begin{array}{l}\text { Multivariable-adjusted HR } \\
(95 \% \mathrm{CI})\end{array}$ & 1 & $\begin{array}{l}0.78 \\
(0.56-1.08)\end{array}$ & $\begin{array}{l}0.60 \\
(0.34-1.05)\end{array}$ & $\begin{array}{l}0.55 \\
(0.33-0.93)\end{array}$ & 0.025 & $\begin{array}{l}0.83 \\
(0.64-1.07)\end{array}$ & 0.054 \\
\hline \multicolumn{8}{|l|}{$\mathrm{PR}+$ breast cancer } \\
\hline No. of cases & 273 & 277 & 69 & 84 & & 703 & \\
\hline $\begin{array}{l}\text { Age-adjusted HR } \\
(95 \% \mathrm{CI})\end{array}$ & 1 & $\begin{array}{l}1.10 \\
(0.90-1.35)\end{array}$ & $\begin{array}{l}0.97 \\
(0.70-1.33)\end{array}$ & $\begin{array}{l}0.89 \\
(0.67-1.20)\end{array}$ & 0.305 & $\begin{array}{l}0.99 \\
(0.89-1.10)\end{array}$ & \\
\hline $\begin{array}{l}\text { Multivariable-adjusted HR } \\
(95 \% \mathrm{CI})\end{array}$ & 1 & $\begin{array}{l}1.06 \\
(0.85-1.33)\end{array}$ & $\begin{array}{l}0.97 \\
(0.68-1.40)\end{array}$ & $\begin{array}{l}0.94 \\
(0.68-1.30)\end{array}$ & 0.576 & $\begin{array}{l}1.01 \\
(0.89-1.15)\end{array}$ & 0.278 \\
\hline \multicolumn{8}{|l|}{ PR- breast cancer } \\
\hline No. of cases & 158 & 128 & 40 & 49 & & 375 & \\
\hline $\begin{array}{l}\text { Age-adjusted HR } \\
(95 \% \mathrm{CI})\end{array}$ & 1 & $\begin{array}{l}0.85 \\
(0.66-1.11)\end{array}$ & $\begin{array}{l}0.92 \\
(0.62-1.36)\end{array}$ & $\begin{array}{l}0.86 \\
(0.60-1.24)\end{array}$ & 0.557 & $\begin{array}{l}1.02 \\
(0.89-1.17)\end{array}$ & \\
\hline $\begin{array}{l}\text { Multivariable-adjusted HR } \\
(95 \% \mathrm{CI})\end{array}$ & 1 & $\begin{array}{l}0.89 \\
(0.67-1.18)\end{array}$ & $\begin{array}{l}0.95 \\
(0.62-1.47)\end{array}$ & $\begin{array}{l}0.87 \\
(0.58-1.31)\end{array}$ & 0.637 & $\begin{array}{l}1.02 \\
(0.88-1.19)\end{array}$ & 0.240 \\
\hline \multicolumn{8}{|l|}{$\mathrm{ER}+\mathrm{PR}+$ breast cancer } \\
\hline No. of cases & 263 & 272 & 68 & 82 & & 685 & \\
\hline $\begin{array}{l}\text { Age-adjusted HR } \\
(95 \% \mathrm{CI})\end{array}$ & 1 & $\begin{array}{l}1.12 \\
(0.91-1.38)\end{array}$ & $\begin{array}{l}0.99 \\
(0.72-1.37)\end{array}$ & $\begin{array}{l}0.91 \\
(0.67-1.22)\end{array}$ & 0.351 & $\begin{array}{l}0.99 \\
(0.89-1.11)\end{array}$ & \\
\hline $\begin{array}{l}\text { Multivariable-adjusted HR } \\
(95 \% \mathrm{CI})\end{array}$ & 1 & $\begin{array}{l}1.08 \\
(0.86-1.36)\end{array}$ & $\begin{array}{l}1.00 \\
(0.69-1.43)\end{array}$ & $\begin{array}{l}0.95 \\
(0.68-1.31)\end{array}$ & 0.596 & $\begin{array}{l}1.01 \\
(0.89-1.15)\end{array}$ & 0.344 \\
\hline \multicolumn{8}{|l|}{$\mathrm{ER}-\mathrm{PR}$ - breast cancer } \\
\hline No. of cases & 76 & 63 & 14 & 17 & & 170 & \\
\hline $\begin{array}{l}\text { Age-adjusted HR } \\
(95 \% \mathrm{CI})\end{array}$ & 1 & $\begin{array}{l}0.86 \\
(0.60-1.24)\end{array}$ & $\begin{array}{l}0.65 \\
(0.35-1.21)\end{array}$ & $\begin{array}{l}0.61 \\
(0.35-1.07)\end{array}$ & 0.064 & $\begin{array}{l}0.89 \\
(0.68-1.16)\end{array}$ & \\
\hline $\begin{array}{l}\text { Multivariable-adjusted HR } \\
(95 \% \mathrm{CI})\end{array}$ & 1 & $\begin{array}{l}0.86 \\
(0.58-1.27)\end{array}$ & $\begin{array}{l}0.61 \\
(0.31-1.18)\end{array}$ & $\begin{array}{l}0.53 \\
(0.29-0.99)\end{array}$ & 0.037 & $\begin{array}{l}0.85 \\
(0.64-1.14)\end{array}$ & 0.100 \\
\hline
\end{tabular}

${ }^{a}$ Multivariable analyses were adjusted for the following: age at baseline (55-59, 60-64, 65-69 years), cigarette smoking (status (never, former, current), frequency (number of cigarettes per day; continuous, centered), duration (number of years; continuous, centered)), body height (continuous, cm), BMI $\left(<18.5,18.5-<25,25-<30, \geq 30 \mathrm{~kg} / \mathrm{m}^{2}\right)$, non-occupational physical activity $(\leq 30,>30-60,>60-90,>90 \mathrm{~min} / \mathrm{day})$, highest level of education (primary school or lower vocational, secondary or medium vocational, and higher vocational or university), family history of breast cancer in mother or sisters (no, yes), history of benign breast disease (no, yes), age at menarche ( $<12,13-14,15-16, \geq 17$ years), parity (nulliparous, $1-2, \geq 3$ children), age at first birth $(<25, \geq 25$ years), age at menopause $(<45,45-49,50-54, \geq 55$ years), oral contraceptive use (never, ever), postmenopausal HRT (never, ever), energy intake (continuous, kcal/day), alcohol intake $(0,0.1-<5,5-<15,15-<30, \geq 30 \mathrm{~g} /$ day), alternate Mediterranean Diet Score excluding alcohol and nuts (0-2, 3-4, 5-7 pts) 


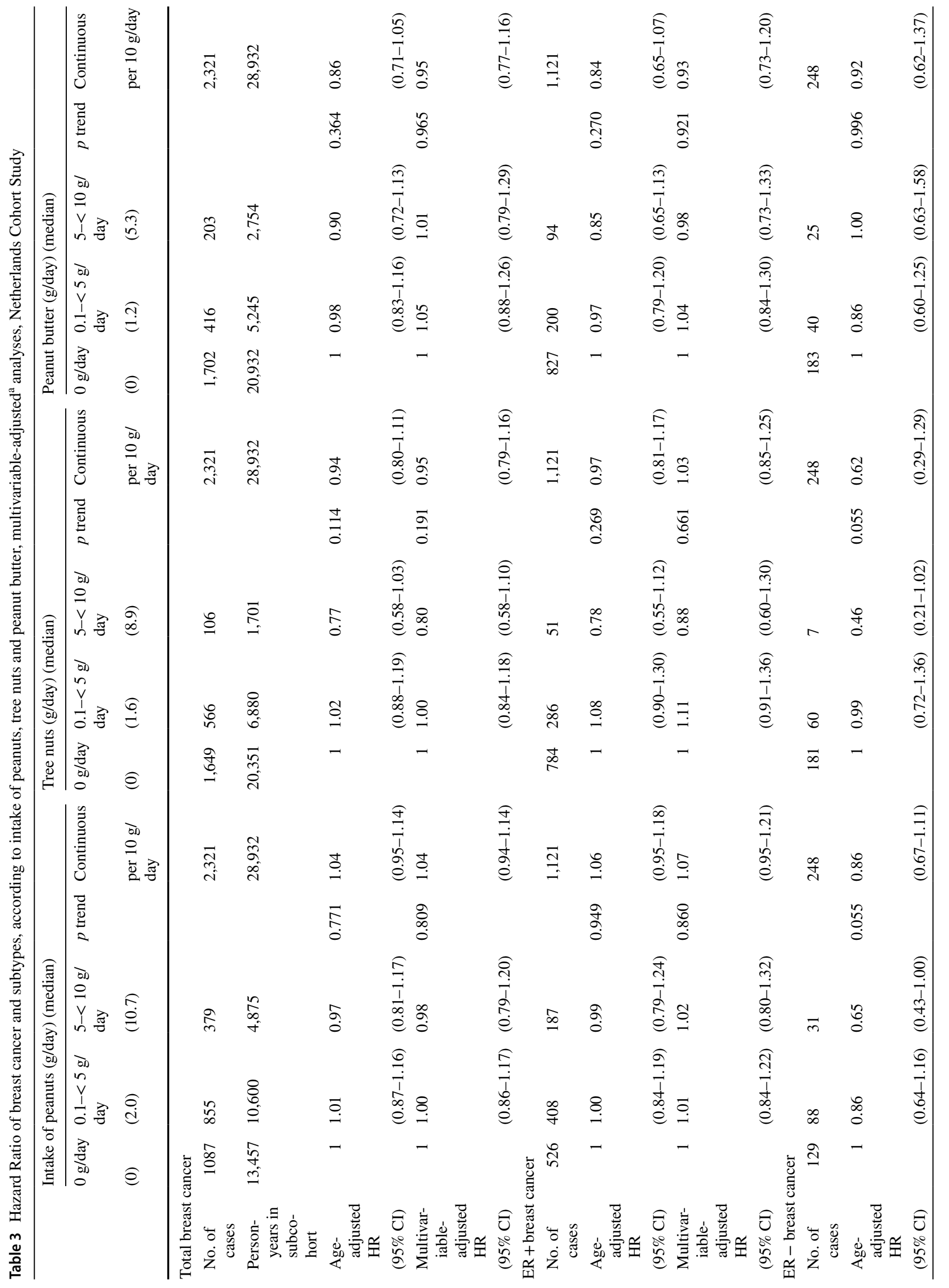




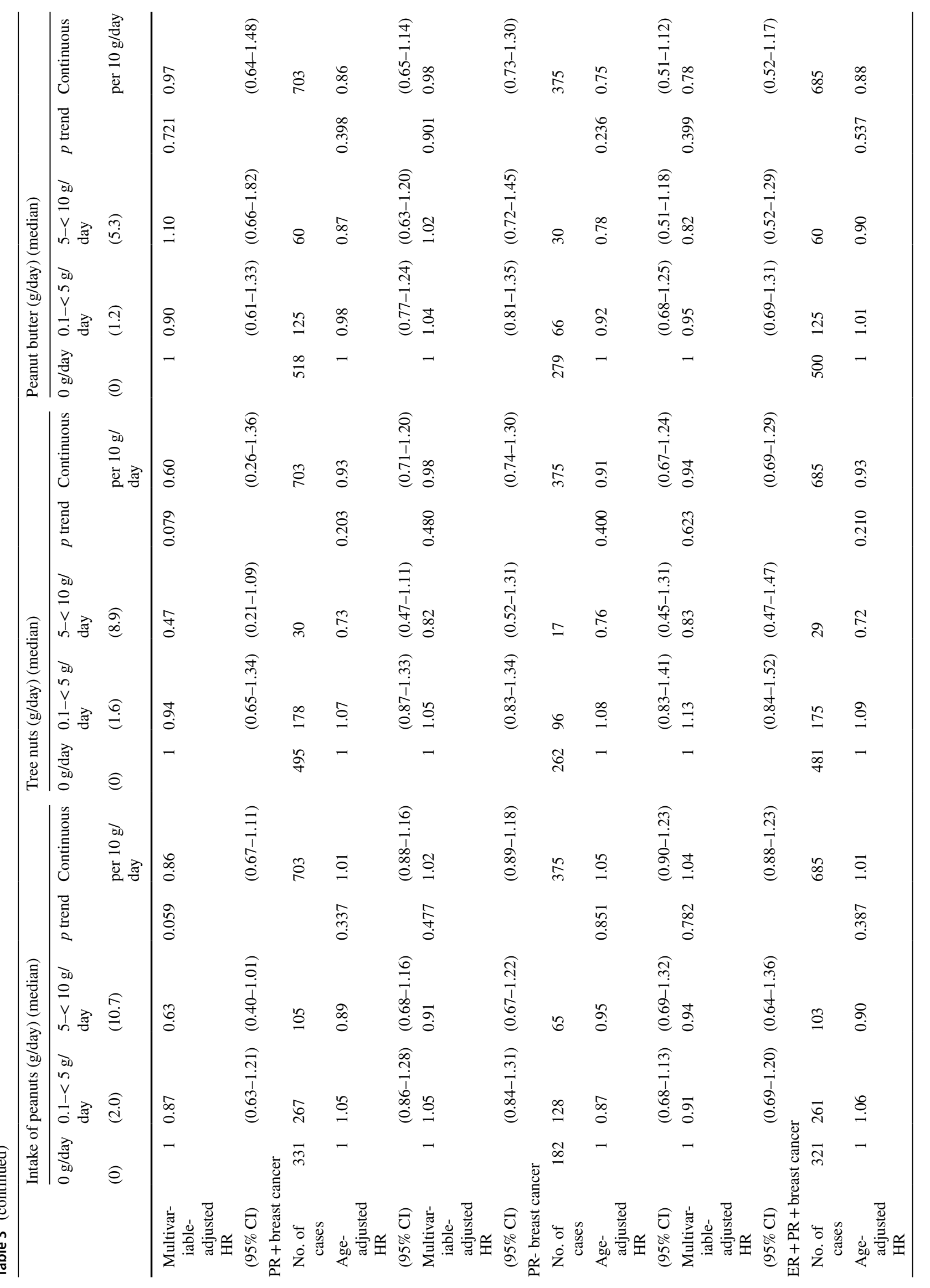




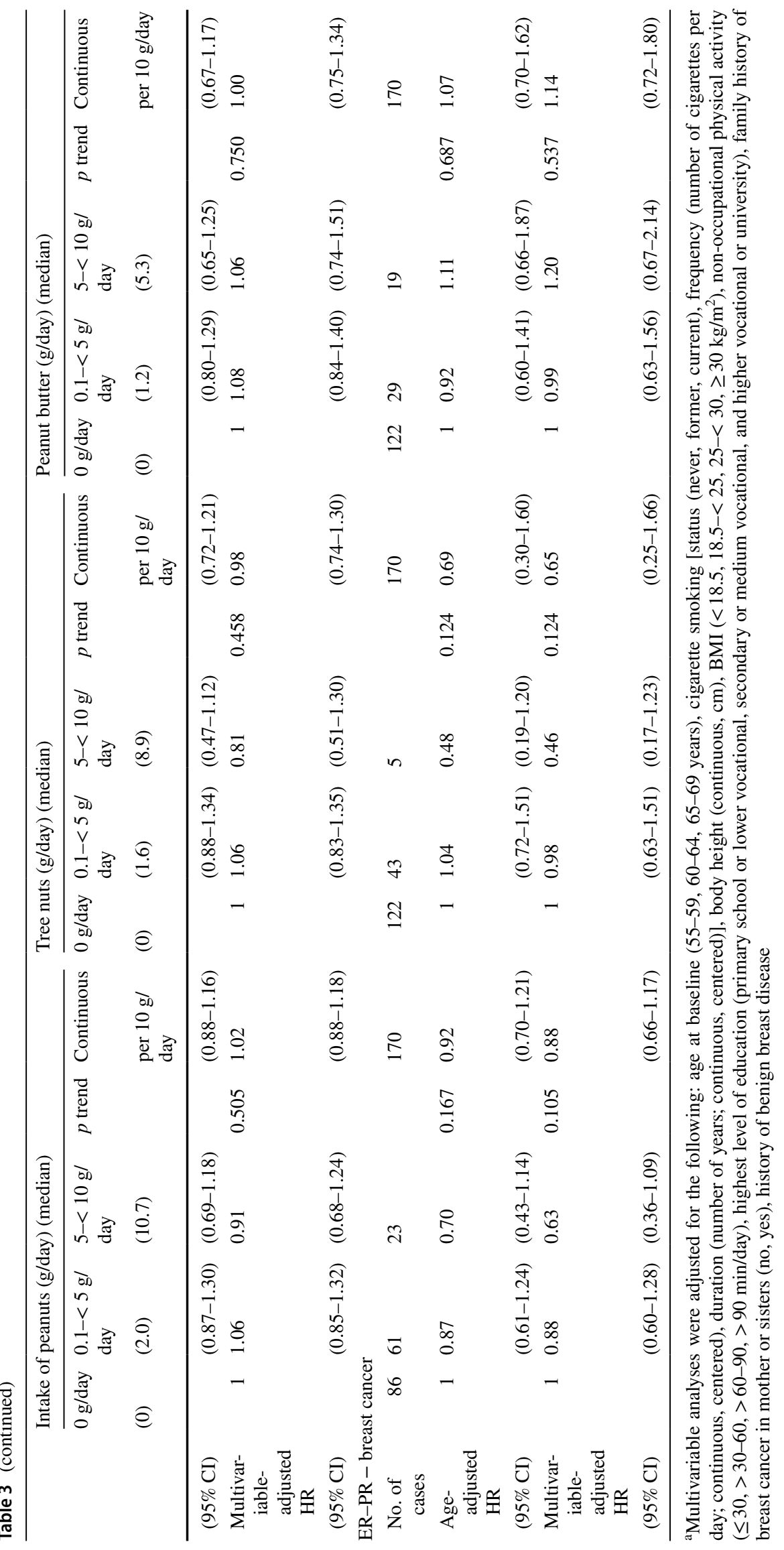



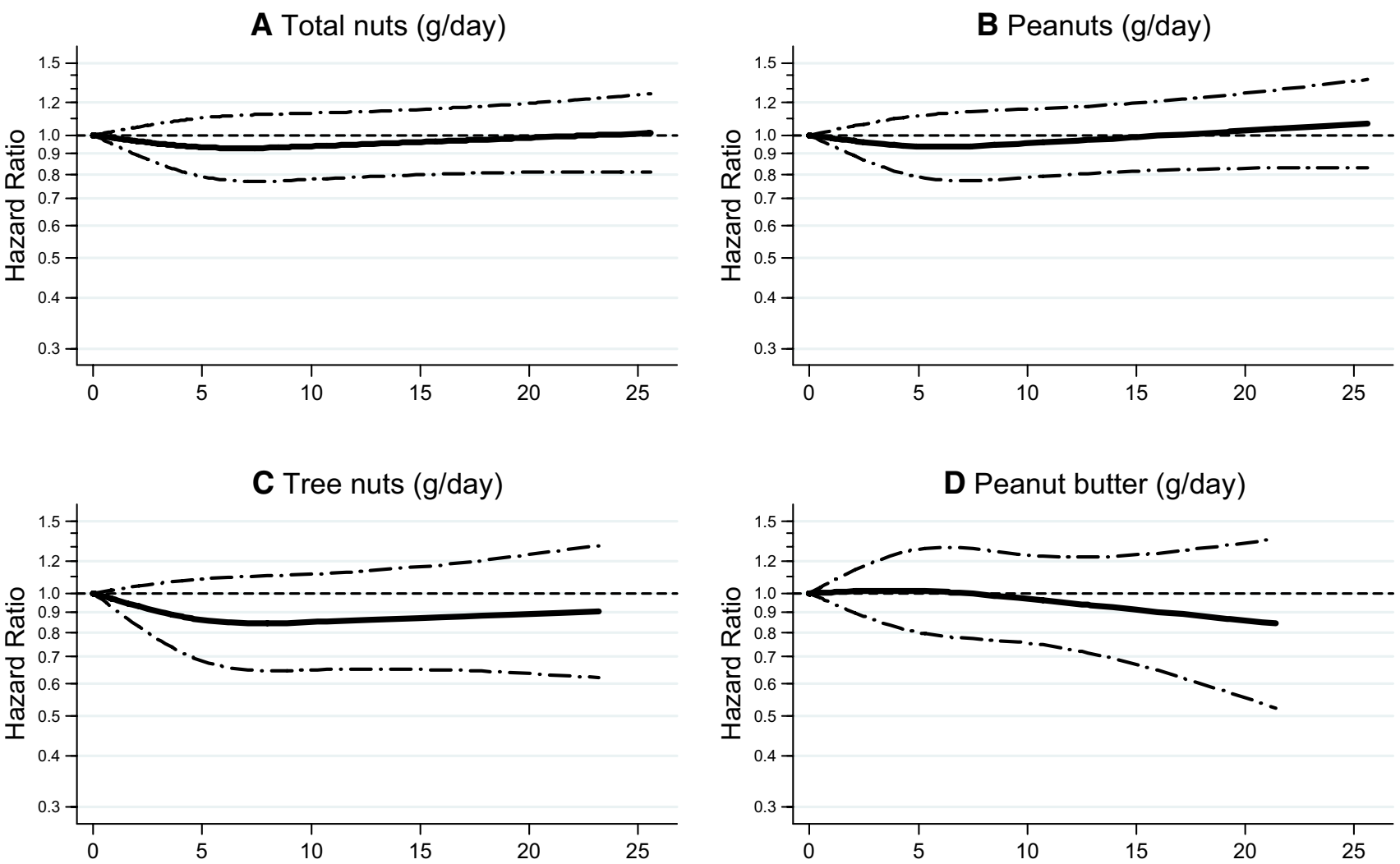

Fig. 1 Non-parametric regression curves for the association between total breast cancer risk and a total nut intake, $\mathbf{b}$ peanuts, $\mathbf{c}$ tree nuts, and d peanut butter intake (g/day). Multivariate HRs are calculated by restricted cubic spline regression (using 3 knots at 0,5 , and $10 \mathrm{~g} /$ day) adjusting for the following: age at baseline (55-59, 60-64, 65-69 years), cigarette smoking [status (never, former, current), frequency (number of cigarettes per day; continuous, centered), duration (number of years; continuous, centered)], body height (continuous, $\mathrm{cm})$, BMI $\left(<18.5,18.5-<25,25-<30, \geq 30 \mathrm{~kg} / \mathrm{m}^{2}\right)$, non-occupational physical activity $(\leq 30,>30-60,>60-90,>90 \mathrm{~min} /$ day $)$, highest level of education (primary school or lower vocational, secondary or medium vocational, and higher vocational or university), family history of breast cancer in mother or sisters (no, yes), history

increased HRs observed for BMI $\geq 25 \mathrm{~kg} / \mathrm{m}^{2}$ [Total: HR 1.32 (0.96-1.81); ER+: HR 1.50 (1.03-2.18)]. For the ER - subtype, inverse associations were seen in most subgroups, and there was no significant interaction with these covariables. Possible interactions with age at baseline (55-59, 60-64, 65-69 years), smoking status (never, ex, current), and family history of breast cancer (no, yes) were also investigated, but were all non-significant.

\section{Discussion}

In this large prospective study, we found a statistically significant inverse association between nut intake and risk of estrogen receptor-negative postmenopausal breast

of benign breast disease (no, yes), age at menarche $(\leq 12,13-14$, $15-16, \geq 17$ years), parity (nulliparous, $1-2, \geq 3$ children), age at first birth $(<25, \geq 25$ years), age at menopause $(<45,45-49,50-54$, $\geq 55$ years), oral contraceptive use (never, ever), postmenopausal hormone replacement therapy (never, ever), energy intake (continuous, $\mathrm{kcal} /$ day $)$, alcohol intake $(0,0.1-<5,5-<15,15-<30, \geq 30 \mathrm{~g} /$ day $)$, alternate Mediterranean Diet Score excluding alcohol and nuts (0-2, $3-4,5-7$ pts). To test for non-linearity, the model including the linear and cubic spline terms was compared to the model with only the linear term using a Wald test. $P$ values for non-linearity were 0.343 for total nut intake, 0.347 for peanut intake, 0.212 for tree nuts and 0.683 for peanut butter intake. Lines with dashes represent the $95 \%$ confidence intervals (CIs) for the fitted non-linear trend (solid line)

cancer. There were no significant inverse associations with $\mathrm{ER}+$ or total breast cancer risk. When comparing those consuming $10+\mathrm{g}$ nuts/day to non-consumers, the HR for ER - breast cancer was 0.55 , while it was 0.91 for total breast cancer and 1.07 for ER + breast cancer. While there was no variation between PR subtypes, the ER-PR - subtype was also significantly inversely associated with nut intake. There was no statistical evidence of non-linear dose-response relationships, but this non-linearity test was borderline significant for ER - breast cancer, where the exposure-response curves show a clear leveling off with intake levels above $10 \mathrm{~g} /$ day. Intake of peanuts and tree nuts separately was also inversely related to ER - breast cancer subtypes, while no associations were found with peanut butter intake. There was significant interaction 

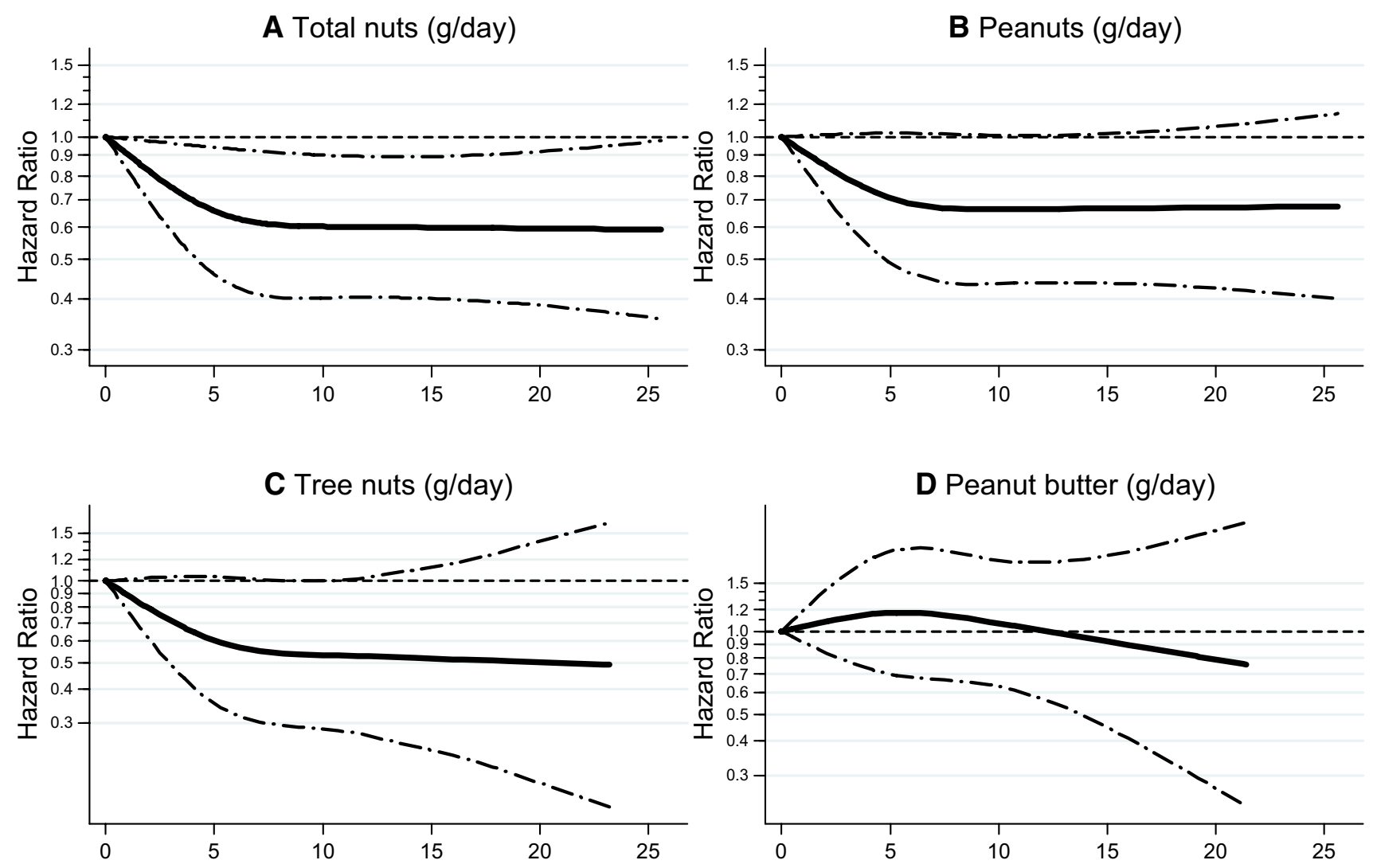

Fig. 2 Non-parametric regression curves for the association between ER - breast cancer risk and a total nut intake, $\mathbf{b}$ peanuts, $\mathbf{c}$ tree nuts, and $\mathbf{d}$ peanut butter intake (grams/day). Multivariate HRs are calculated by restricted cubic spline regression (using 3 knots at 0,5 , and $10 \mathrm{~g}$ /day) adjusting for: age at baseline (55-59, 60-64, 65-69 years), cigarette smoking [status (never, former, current), frequency (number of cigarettes per day; continuous, centered), duration (number of years; continuous, centered)], body height (continuous, $\mathrm{cm}$ ), BMI $\left(<18.5,18.5-<25,25-<30, \geq 30 \mathrm{~kg} / \mathrm{m}^{2}\right)$, non-occupational physical activity $(\leq 30,>30-60,>60-90,>90 \mathrm{~min} /$ day $)$, highest level of education (primary school or lower vocational, secondary or medium vocational, and higher vocational or university), family history of breast cancer in mother or sisters (no, yes), history of benign breast

between total nut intake and BMI for total breast cancer and $\mathrm{ER}+$ breast cancer risk.

The PREDIMED randomized controlled trial in Spain investigated whether following a Mediterranean diet supplemented with nuts compared to a control diet in which it was advised to decrease dietary fat reduced the risk of breast cancer [9]. After a median follow-up of 4.8 years with 35 incident breast cancer cases, they found a RR of 0.59 (95\% CI 0.26-1.35). Although this association was not significant, the HR was rather low and power was probably insufficient given the low number of cases. Since diets were analyzed and no direct comparisons between consumption of individual food items in both groups were made, it is unclear what the effect of nut consumption alone would be.

disease (no, yes), age at menarche ( $\leq 12,13-14,15-16, \geq 17$ years), parity (nulliparous, $1-2, \geq 3$ children), age at first birth $(<25$, $\geq 25$ years), age at menopause $(<45,45-49,50-54, \geq 55$ years), oral contraceptive use (never, ever), postmenopausal hormone replacement therapy (never, ever), energy intake (continuous, kcal/day), alcohol intake $(0,0.1-<5,5-<15,15-<30, \geq 30 \mathrm{~g} /$ day $)$, alternate Mediterranean Diet Score excluding alcohol and nuts (0-2, 3-4, 5-7 pts). To test for non-linearity, the model including the linear and cubic spline terms was compared to the model with only the linear term using a Wald test. $P$ values for non-linearity were 0.054 for total nut intake, 0.099 for peanut intake, 0.202 for tree nuts, and 0.474 for peanut butter intake. Lines with dashes represent the $95 \%$ confidence intervals (CIs) for the fitted non-linear trend (solid line)

In two cohort studies, the relationship between nut consumption and risk of breast cancer was studied. Sonestedt et al. [6] in Sweden did not find a relation between nut intake and risk of breast cancer (HR for median consumption of $6 \mathrm{~g} /$ day vs. non-consumers $=0.98,95 \%$ CI $0.75-1.27$ ). Also, no relation was found when stratifying on ER status [6]. In the Nurses' Health Study II, no association was observed between the number of servings of peanuts, peanut butter, and other nuts per day in young adulthood and risk of breast cancer in both premenopausal and postmenopausal women [7].

Besides these cohort studies, six case-control studies on this topic were identified. A case-control study in Argentina found non-significantly increased breast cancer risks with higher nut (peanut and walnut) consumption when 


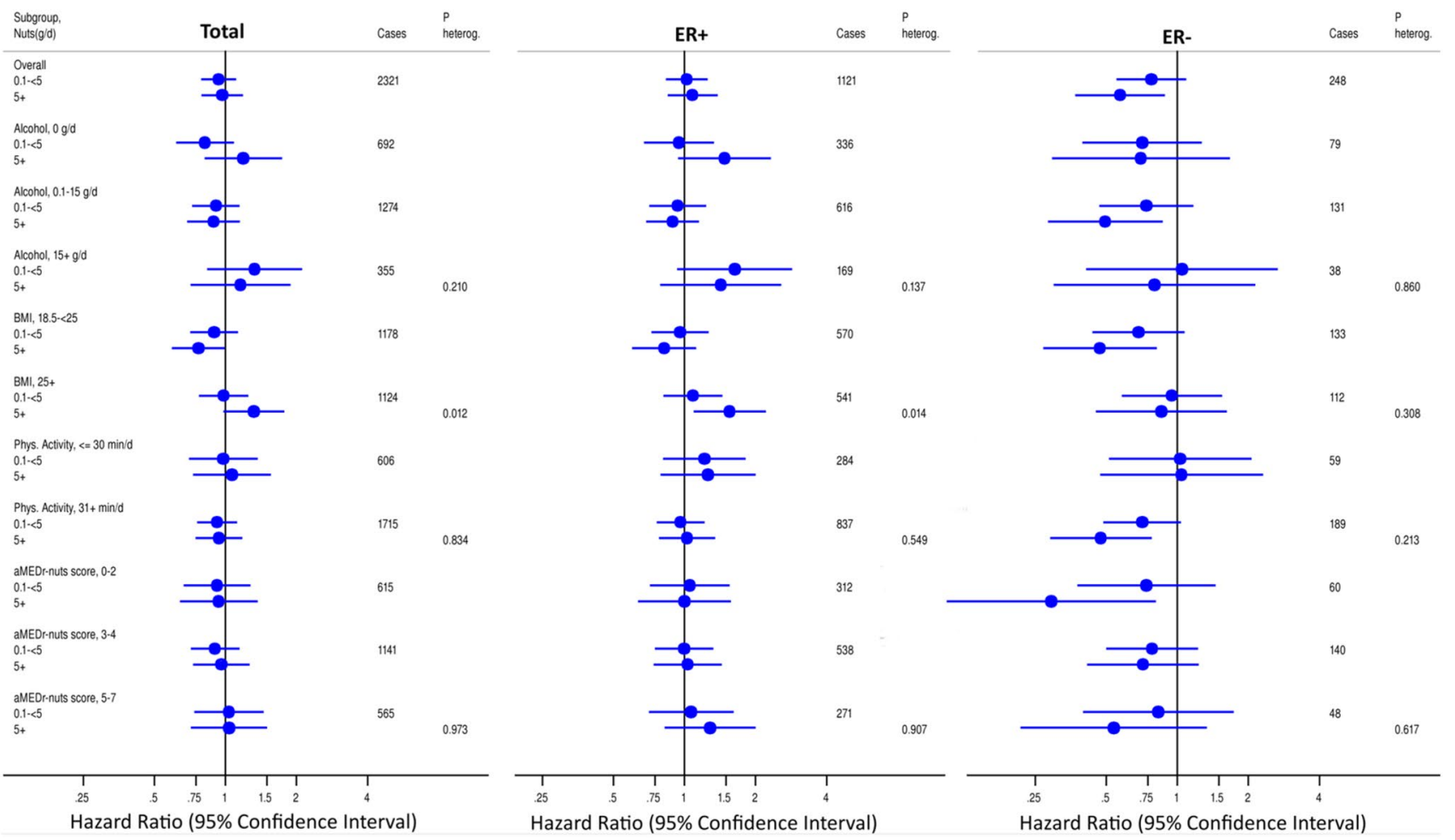

Fig. 3 Hazard ratios and 95\% confidence intervals of breast cancer, comparing total nut intake categories of $0.1-<5$, and $5+\mathrm{g}$ /day versus $0 \mathrm{~g} / \mathrm{day}$, in subgroups of potential effect modifiers. Multivariable analyses were adjusted for the following: age at baseline (55-59, 60-64, 65-69 years), cigarette smoking [status (never, former, current), frequency (number of cigarettes per day; continuous, centered), duration (number of years; continuous, centered)], body height (continuous, cm), BMI $\left(<18.5,18.5-<25,25-<30, \geq 30 \mathrm{~kg} / \mathrm{m}^{2}\right)$, nonoccupational physical activity $(\leq 30,>30-60,>60-90,>90 \mathrm{~min} /$ day), highest level of education (primary school or lower vocational,

comparing cases to both hospital and neighborhood controls [24]. An Italian case-control study found a significantly inverse association between seed oil consumption, including peanut oil, and breast cancer risk in both pre- and postmenopausal women [25]. In Canada, a significantly inverse relation was found between consumption frequency of total nuts during adolescence and breast cancer risk, which was mainly observed for postmenopausal breast cancer [8]. In Mexico, risk of breast cancer was significantly inversely related to the consumption frequency of peanuts, walnuts, and almonds [26]. Studies in Iran and the Central African Republic showed positive associations between (ground)nut intake and breast cancer, but no confounder adjustment was made [27, 28].

Two cohort studies were performed on nut intake and risk of benign breast disease, both in the US. Su et al. [10] found a statistically significant decreased risk of proliferative BBD when consuming nuts more often as adolescent (RR for $\geq 2 /$ week vs. $<1 /$ month $=0.64,95 \%$ CI $0.48-0.85$ ), but secondary or medium vocational, and higher vocational or university), family history of breast cancer in mother or sisters (no, yes), history of benign breast disease (no, yes), age at menarche $(\leq 12$, $13-14,15-16, \geq 17$ years), parity (nulliparous, $1-2, \geq 3$ children), age at first birth $(<25, \geq 25$ years), age at menopause $(<45,45-49$, $50-54, \geq 55$ years), oral contraceptive use (never, ever), postmenopausal hormone replacement therapy (never, ever), energy intake (continuous, kcal/day), alcohol intake $(0,0.1-<5,5-<15,15-<30$, $\geq 30 \mathrm{~g}$ /day), alternate Mediterranean Diet Score excluding alcohol and nuts $(0-2,3-4,5-7$ pts $)$

this relation was not found for peanut butter consumption [10]. An inverse association between nut consumption in adolescence and subsequent BBD risk was also observed by Berkey [29].

Thus, the literature is mixed with null results in two cohort studies and inverse and positive associations in case-control studies (which may be linked to storage conditions of nuts in developing countries), but very few studies have investigated hormone receptor subtypes.

We also found no association with total breast cancer, but did find an inverse association with ER - subtypes. This needs to be confirmed in other large cohort studies and trials, with analyses per receptor subtype. We did not have data on nut intake in adolescence or early adulthood, which might be etiologically relevant; future studies might also focus on that.

In the NLCS, we earlier reported inverse associations with MD adherence in the ER - subtypes [11]. In the current effect-modification analysis, inverse associations with 
ER - breast cancer were seen in every subgroup of aMED excluding nuts (and alcohol), with the strongest inverse association found in those who had the lowest MD adherence score. This suggests an independent association between ER - breast cancer risk and nuts, apart from other MDcomponents. Nuts are a rich source of nutrients and energy, for example mono- and polyunsaturated fatty acids, protein, fiber, vitamins (e.g., various B-vitamins and vitamin E), minerals (e.g., magnesium, selenium), antioxidants, and phytochemicals like phenolic compounds and phytosterols [30], although the concentrations can vary among the different sorts of nuts [31]. The potential mechanisms of action of these components of nuts in the prevention of cancer have been investigated, but not in great detail. Some of them are related to antioxidant activity, the regulation of cell differentiation and proliferation, the reduction of tumor initiation or promotion, the repair of DNA damage, anti-inflammatory responses, the regulation of immunological activity, the induction or inhibition of metabolic enzymes and hormonal mechanisms [32, 33].

Although nuts have a high fat content, they contain mainly monounsaturated (MUFA) or polyunsaturated fatty acids (PUFA), and are very low in saturated fat [34]. When comparing peanuts to walnuts, it can be concluded that both are good sources of magnesium, MUFA and PUFA, but that walnuts contain more alpha-linolenic acid; peanuts are richer in MUFA, protein, niacin, and potassium. The antioxidant capacity of walnuts is higher than peanuts or peanut butter [5]. Peanuts, grapes, and red wine are primary sources of resveratrol. Resveratrol (a stilbene) has been shown to induce apoptosis, inhibit cell invasion and angiogenesis and has been tested in in vivo models of breast, colorectal, liver, pancreatic, and prostate cancer. In addition, resveratrol and anacardic acid (a phenolic acid in cashews) seem to be able to counteract cancer-related epigenetic alterations [35]. Epidemiologic studies and the PREDIMED trial have suggested an inverse association between nut consumption and inflammation [36]. Finally, inositol polyphosphates (from peanuts) might be related to energy metabolism and cancer through the inhibition of the PI3K/Akt pathway [35].

The prospective design and high completeness of followup of the NLCS make information bias and selection bias unlikely. A potential weakness is the moderate proportion of breast cancer cases for whom ER/PR status was known. Breast cancer cases with known and unknown receptor status did not differ importantly according to baseline and tumor characteristics, making selection bias of the cases unlikely (data not shown). Although many possible confounders were taken into account, the possibility of confounding by unmeasured factors remains. The validation study of the food frequency questionnaire has shown that it performs relatively well [16], but measurement error may still have attenuated associations. The lack of possibilities to update dietary intake or other lifestyle data during follow-up may have resulted in some attenuated associations too.

In conclusion, our cohort study showed a statistically significant inverse association between total nut intake and risk of ER - breast cancer. There were no significant inverse associations with ER + or total breast cancer risk. While there was no variation between PR subtypes, the ER-PR - subtype was also significantly inversely associated with nut intake. For ER - breast cancer, the exposure-response curves using restricted cubic splines showed a clear leveling off with intake levels above $10 \mathrm{~g} /$ day, but the non-linearity test was not significant. Intake of peanuts and tree nuts separately was also inversely related to ER - breast cancer subtypes, while no associations were found with peanut butter intake.

Acknowledgments We thank the participants of this study and The Netherlands Cancer Registry and Dutch Pathology Registry PALGA for providing data, and we thank the staff of The Netherlands Cohort Study for their valuable contributions.

Funding This study was funded by the Dutch Cancer Society (Grant Number UM 2015-7860). The funder had no role in the design, implementation, analysis, or interpretation of the data.

\section{Compliance with ethical standards}

Conflict of interest There are no competing financial interests in relation to this work.

Open Access This article is distributed under the terms of the Creative Commons Attribution 4.0 International License (http://creativecommons.org/licenses/by/4.0/), which permits unrestricted use, distribution, and reproduction in any medium, provided you give appropriate credit to the original author(s) and the source, provide a link to the Creative Commons license, and indicate if changes were made.

\section{References}

1. Aune D, Keum N, Giovannucci E, Fadnes LT, Boffetta P, Greenwood DC, Tonstad S, Vatten LJ, Riboli E, Norat T (2016) Nut consumption and risk of cardiovascular disease, total cancer, all-cause and cause-specific mortality: a systematic review and dose-response meta-analysis of prospective studies. BMC Med 14(1):207. https://doi.org/10.1186/s12916-016-0730-3

2. Estruch R, Ros E, Salas-Salvado J, Covas MI, Corella D, Aros F, Gomez-Gracia E, Ruiz-Gutierrez V, Fiol M, Lapetra J, LamuelaRaventos RM, Serra-Majem L, Pinto X, Basora J, Munoz MA, Sorli JV, Martinez JA, Martinez-Gonzalez MA, Investigators PS (2013) Primary prevention of cardiovascular disease with a Mediterranean diet. New Engl J Med 368(14):1279-1290. https://doi. org/10.1056/NEJMoa1200303

3. Bao Y, Han J, Hu FB, Giovannucci EL, Stampfer MJ, Willett WC, Fuchs CS (2013) Association of nut consumption with total and cause-specific mortality. New Engl J Med 369(21):2001-2011. https://doi.org/10.1056/NEJMoa1307352

4. Guasch-Ferre M, Bullo M, Martinez-Gonzalez MA, Ros E, Corella D, Estruch R, Fito M, Aros F, Warnberg J, Fiol M, Lapetra J, Vinyoles E, Lamuela-Raventos RM, Serra-Majem L, Pinto 
X, Ruiz-Gutierrez V, Basora J, Salas-Salvado J, group Ps (2013) Frequency of nut consumption and mortality risk in the PREDIMED nutrition intervention trial. BMC Med 11:164. https://doi. org/10.1186/1741-7015-11-164

5. van den Brandt PA, Schouten LJ (2015) Relationship of tree nut, peanut and peanut butter intake with total and cause-specific mortality: a cohort study and meta-analysis. Int J Epidemiol 44(3):1038-1049. https://doi.org/10.1093/ije/dyv039

6. Sonestedt E, Borgquist S, Ericson U, Gullberg B, Landberg G, Olsson H, Wirfalt E (2008) Plant foods and oestrogen receptor alpha- and beta-defined breast cancer: observations from the Malmo Diet and Cancer cohort. Carcinogenesis 29(11):22032209. https://doi.org/10.1093/carcin/bgn196

7. Farvid MS, Cho E, Chen WY, Eliassen AH, Willett WC (2014) Dietary protein sources in early adulthood and breast cancer incidence: prospective cohort study. BMJ 348:g3437. https://doi. org/10.1136/bmj.g3437

8. Liu Y, Colditz GA, Cotterchio M, Boucher BA, Kreiger N (2014) Adolescent dietary fiber, vegetable fat, vegetable protein, and nut intakes and breast cancer risk. Breast Cancer Res Treat 145(2):461-470. https://doi.org/10.1007/s10549-014-2953-3

9. Toledo E, Salas-Salvado J, Donat-Vargas C, Buil-Cosiales P, Estruch R, Ros E, Corella D, Fito M, Hu FB, Aros F, GomezGracia E, Romaguera D, Ortega-Calvo M, Serra-Majem L, Pinto X, Schroder H, Basora J, Sorli JV, Bullo M, Serra-Mir M, Martinez-Gonzalez MA (2015) Mediterranean diet and invasive breast cancer risk among women at high cardiovascular risk in the PREDIMED trial: a randomized clinical trial. JAMA Intern Med 175(11):1752-1760. https://doi.org/10.1001/ jamainternmed.2015.4838

10. Su X, Tamimi RM, Collins LC, Baer HJ, Cho E, Sampson L, Willett WC, Schnitt SJ, Connolly JL, Rosner BA, Colditz GA (2010) Intake of fiber and nuts during adolescence and incidence of proliferative benign breast disease. Cancer Causes Control 21(7):1033-1046. https://doi.org/10.1007/s10552-010-9532-7

11. van den Brandt PA, Schulpen M (2017) Mediterranean diet adherence and risk of postmenopausal breast cancer: results of a cohort study and meta-analysis. Int J Cancer 140(10):2220-2231. https:// doi.org/10.1002/ijc.30654

12. van den Brandt PA, Goldbohm RA, van 't Veer P, Volovics A, Hermus RJ, Sturmans F (1990) A large-scale prospective cohort study on diet and cancer in The Netherlands. J Clin Epidemiol 43(3):285-295

13. Prentice RL (1986) A case-cohort design for epidemiologic studies and disease prevention trials. Biometrika 73(1):1-11

14. van den Brandt PA, Schouten LJ, Goldbohm RA, Dorant E, Hunen PM (1990) Development of a record linkage protocol for use in the Dutch Cancer Registry for Epidemiological Research. Int J Epidemiol 19(3):553-558

15. van den Brandt PA, van't Veer P, Goldbohm RA, Dorant E, Volovics A, Hermus RJ, Sturmans F (1993) A prospective cohort study on dietary fat and the risk of postmenopausal breast cancer. Cancer Res 53(1):75-82

16. Goldbohm RA, van den Brandt PA, Brants HA, van't Veer P, Al M, Sturmans F, Hermus RJ (1994) Validation of a dietary questionnaire used in a large-scale prospective cohort study on diet and cancer. Eur J Clin Nutr 48(4):253-265

17. Volovics A, van den Brandt PA (1997) Methods for the analyses of case-cohort studies. Biometrical J 39(2):159-214

18. Nevo-Table (1986) Dutch food composition table 1986-1987; Nederlands voedingsstoffenbestand. pp 1986-1987

19. Schoenfeld D (1982) Partial residuals for the proportional hazards regression model. Biometrika 69:239-241

20. Lin D, Wei L (1989) The robust inference for the Cox proportional hazards model. J Am Stat Assoc 84(408):1074-1078
21. Fung TT, McCullough ML, Newby PK, Manson JE, Meigs JB, Rifai N, Willett WC, Hu FB (2005) Diet-quality scores and plasma concentrations of markers of inflammation and endothelial dysfunction. Am J Clin Nutr 82(1):163-173

22. de Vogel S, Bongaerts BW, Wouters KA, Kester AD, Schouten LJ, de Goeij AF, de Bruine AP, Goldbohm RA, van den Brandt PA, van Engeland M, Weijenberg MP (2008) Associations of dietary methyl donor intake with MLH1 promoter hypermethylation and related molecular phenotypes in sporadic colorectal cancer. Carcinogenesis 29(9):1765-1773

23. Wacholder S, Gail M, Pee D, Brookmeyer R (1989) Alternative variance and efficiency calculations for the case-cohort design. Biometrika 76(1):117-123

24. Iscovich JM, Iscovich RB, Howe G, Shiboski S, Kaldor JM (1989) A case-control study of diet and breast cancer in Argentina. Int J Cancer 44(5):770-776

25. la Vecchia C, Negri E, Franceschi S, Decarli A, Giacosa A, Lipworth L (1995) Olive oil, other dietary fats, and the risk of breast cancer (Italy). Cancer Causes Control 6(6):545-550

26. Soriano-Hernandez AD, Madrigal-Perez DG, Galvan-Salazar HR, Arreola-Cruz A, Briseno-Gomez L, Guzman-Esquivel J, Dobrovinskaya O, Lara-Esqueda A, Rodriguez-Sanchez IP, Baltazar-Rodriguez LM, Espinoza-Gomez F, Martinez-Fierro ML, de-Leon-Zaragoza L, Olmedo-Buenrostro BA, Delgado-Enciso I (2015) The protective effect of peanut, walnut, and almond consumption on the development of breast cancer. Gynecol Obstet Invest 80(2):89-92. https://doi.org/10.1159/000369997

27. Salarabadi A, Bidgoli SA, Madani SH (2015) Roles of kermanshahi oil, animal fat, dietary and non- dietary vitamin D and other nutrients in increased risk of premenopausal breast cancer: a case control study in Kermanshah, Iran. Asian Pac J Cancer Prev 16(17):7473-7478

28. Balekouzou A, Yin P, Afewerky HK, Bekolo C, Pamatika CM, Nambei SW, Djeintote M, Doui Doumgba A, Mossoro-Kpinde CD, Shu C, Yin M, Fu Z, Qing T, Yan M, Zhang J, Chen S, Li H, Xu Z, Koffi B (2017) Behavioral risk factors of breast cancer in Bangui of Central African Republic: a retrospective case-control study. PLoS ONE 12(2):e0171154. https://doi.org/10.1371/journal.pone. 0171154

29. Berkey CS, Willett WC, Tamimi RM, Rosner B, Frazier AL, Colditz GA (2013) Vegetable protein and vegetable fat intakes in pre-adolescent and adolescent girls, and risk for benign breast disease in young women. Breast Cancer Res Treat 141(2):299-306. https://doi.org/10.1007/s10549-013-2686-8

30. Awad AB, Chan KC, Downie AC, Fink CS (2000) Peanuts as a source of beta-sitosterol, a sterol with anticancer properties. Nutr Cancer 36(2):238-241. https://doi.org/10.1207/ S15327914NC3602_14

31. Dreher ML, Maher CV, Kearney P (1996) The traditional and emerging role of nuts in healthful diets. Nutr Rev 54(8):241-245

32. Kris-Etherton PM, Hecker KD, Bonanome A, Coval SM, Binkoski AE, Hilpert KF, Griel AE, Etherton TD (2002) Bioactive compounds in foods: their role in the prevention of cardiovascular disease and cancer. Am J Med 113(Suppl 9B):71S-88S

33. Gonzalez CA, Salas-Salvado J (2006) The potential of nuts in the prevention of cancer. Br J Nutr 96(Suppl 2):S87-94

34. Ros E (2010) Health benefits of nut consumption. Nutrients 2(7):652-682. https://doi.org/10.3390/nu2070683

35. Falasca M, Casari I, Maffucci T (2014) Cancer chemoprevention with nuts. J Natl Cancer Inst 106(9):dju238. https://doi. org/10.1093/jnci/dju238

36. Estruch R (2010) Anti-inflammatory effects of the Mediterranean diet: the experience of the PREDIMED study. Proc Nutr Soc 69(3):333-340. https://doi.org/10.1017/S0029665110001539 